\title{
PENGARUH BERBAGAI KONSENTRASI AIR PERASAN DAUN PANDAN WANGI (Pandanus ammaryllifolius) SEBAGAI INSEKTISIDA TERHADAP KEMATIAN KECOA TAHUN 2017
}

\author{
Kintani Kemalasari ${ }^{*}$, Djamaluddin Ramlan ${ }^{* *}$ ) \\ Jurusan Kesehatan Lingkungan, Politeknik Kesehatan Kemenkes Semarang, \\ Jl.Raya Baturaden KM 12 Purwokerto, Indonesia
}

\begin{abstract}
Abstrak
Insektisida nabati (daun pandan wangi) dengan komposisi kimia tannin, flavonoid, saponin, alkaloid, polifenol, dan zat warna mampu mematikan kecoa. Tujuan penelitian menemukan cara membunuh kecoa menggunakan bahan nabati (daun pandan wangi). Jenis penelitian pra eksperimental dengan rancangan one shot case study. Populasi dan sampel penelitian yaitu kecoa dewasa Periplaneta americana. Hasil penelitian ini kematian kecoa yang tertinggi pada konsentrasi 35\% yaitu 4 ekor dengan lama paparan 3 jam dan 5 jam, konsentrasi $5 \%$ yaitu 0 ekor, 10\% yaitu 0 ekor, 15\% yaitu 0 ekor, 20\% yaitu 0 ekor, 25\% yaitu 0 ekor, 30\% yaitu 2 ekor dengan lama paparan 4 jam. Hasil analisis statistik terbukti tidak signifikan dengan nilai $K=0,162 \geq \alpha 0,05$, sehingga tidak ada pengaruh antara air perasan daun pandan wangi terhadap kematian kecoa. Hasil penelitian ini dapat disimpulkan bahwa konsentrasi yang efektif untuk mematikan kecoa yaitu 35\%. Perlu dilakukan penelitian lanjut supaya mendapatkan hasil yang maksimal.
\end{abstract}

Kata kunci: Kematian kecoa, air perasan daun pandan wangi, Kesehatan Lingkungan

\begin{abstract}
The Effectiveness of Varios Consentration of Pandanus Leaves (Pandanus ammaryllifolius) Stillitation Water as Insecticide Toward The Death of Cockroach in Year 2017 Concerning plant insecticide (Pandanus leave) which have chemical composition as tannin, flavonoid, saponin, alkaloid and colour substance is able to kill cockroach. The aim of this research is to find the method to kill cockroach using concerning plant material (pandanus leave). The method of this research is pra experimental research with one shot case study plan. The population abd the sample of this research are Periplaneta Americana. Hasil penelitian ini kematian kecoa yang tertinggi pada konsentrasi 35\% yaitu 4 ekor dengan lama paparan 3 jam dan 5 jam, konsentrasi 5\% yaitu 0 ekor, $10 \%$ yaitu 0 ekor, 15\% yaitu 0 ekor, 20\% yaitu 0 ekor, 25\% yaitu 0 ekor, 30\% yaitu 2 ekor dengan lama paparan $4 \mathrm{jam}$. The result of statistic analysis proved there is not signifacance with $K=0,162 \geq \alpha 0.05$, with the result that there is no effect betweem pandanus leave stillitation water toward the death of coackroach. It can be concluded from this research that the effective consentration to kill coackroach is $35 \%$. In need to do further research to get the maximal result.
\end{abstract}

Keywords: Coackroach death, pandanus leave stillitation water, Environmental Health

\section{Pendahuluan}

Menurut

Permenkes

RI

No.374/MENKES/PER/III/2010 penyakit yang

ditularkan melalui vektor masih menjadi penyakit endemis yang dapat menimbulkan wabah atau kejadian luar biasa serta dapat menimbulkan gangguan kesehatan masyarakat, sehingga perlu dilakukan upaya pengendalian atas penyebaran vektor.

*) E-mail: kintani.k@gmail.com

**)E-mail: djamaliddiramlan@gmail.com
Salah satu penyakit yang dapat menimbulkan wabah atau kejadian luar biasa (KLB) yaitu penyakit Diare.

Pada tahun 2013 terjadi 8 KLB yang tersebar di 6 Propinsi, 8 Kabupaten dengan jumlah penderitaan 646 orang dengan kematian 7 orang. Sedangkan pada tahun 2014 terjadi 6 KLB Diare yang tersebar di 5 Propinsi, 6 Kabupaten/Kota, dengan jumlah penderita 2.549 orang dengan kematian 29 orang. (Profil Kesehatan Indonesia Tahun 2014) 
Pada penelitian terdahulu di Singapura air perasan daun pandan wangi berfungsi sebagai bahan penolak(reppelent) bagi kecoa, dengan berbagai konsentrasi $(2 \%, 4 \%, 6 \%, 8 \%, 10 \%)$ didapatkan hasil bahwa efek repelensinya paling tinggi yaitu dengan konsentrasi sekitar 6\% (Li J dan Ho, 2003).

Kecoa adalah serangga dengan bentuk tubuh oval, pipih dorsoventral. Kepalanya tersembunyi di bawah pronotum, dilengkapi dengansepasang mata majemuk dan satu mata tunggal, antene panjang, sayapdua pasang dan tiga pasang kaki. Pronotum dan sayap licin, tidak berambut dan tidak bersisik, berwarna coklat sampai coklat tua. (Ditjen PPM dan PLP, 2002, h. 4)

Kecoa sangat dekat dengan kehidupan manusia, menyukai bangunan yang lembab, berbau dan banyak terdapat makanan. Hidupnya berkelompok dan aktif pada malam hari. Pada siang hari bersembunyi di balik kayu, lubang pada dinding, dibalik pintu atau tempat duduk, di bagian-bagian tertentu dikamar mandi, dan lemari. (Nugroho Susetya Putra, 1994)

Kecoa merupakan salah satu serangga yang berperan sebagai vektor penyakit yang banyak ditemukan dalam rumah, gedung - gedung, termasuk didalam restoran atau rumah makan. Kecoa sebagai vektor perantara yang dapat mengontaminasi makanan manusia dengan membawa agent penyakit yang berhubungan dengan pencernaan seperti diare,demam typoid, disentri, dan kolera. (Rozendaal, 1997)

Kecoa amerika (Periplaneta americana L.), kecoa jerman (Blatella germanica L.), dan kecoa australia (Periplaneta australasiae F.) merupakan jenisjenis kecoa yang sering ditemukan di lingkungan pemukiman. Kecoa amerika merupakan jenis kecoa yang paling banyak ditemukan pada lingkungan pemukiman Indonesia. (Amalia dan Harahap, 2010)

Berbagai cara dilakukan untuk mengendalikan kecoa, secara sanitasi, biologis, mekanis, atau kimiawi. Pada umumnya cara kimiawi lebih banyak dilakukan oleh masyarakat seperti penyemprotan atau pengasapan, karena dinilai lebih praktis. (Enviromental Health Watch, 2005). Kimia Anorganik (Chlorpyrifos, Diazinon, Lidane, DDT) yang berdampak alergi pada manusia dan bersifat merusak hara yang terdapat didalam tanah (tanaman tidak bisa tumbuh/tanah mengeras). Kimia Organik seperti tanaman sirih, pandan dan tanaman lain yang dalam komposisi kimia mengandung bahan yang dapat membunuh kecoa. Upaya pengendalian vektor dengan memanfaatkan tumbuhan bersifat lebih ramah lingkungan, sehingga tidak akan memberi efek negatif terhadap lingkungan.

Salah satu tanaman yang komposisi kimia, bisa membunuh kecoa adalah tanaman pandan wangi. Dalam tanaman pandan wangi mengandung bahan kimia seperti tannin, flavonoid, saponin, alkaloida, polifenol, dan zat warna yang dapat berfungsi sebagai insektisida terhadap kecoa (Arief Hariana, 2011). Saponin adalah suatu sapogenin glikosida, yaitu glikosida yang tersebar luas pada tumbuhan. Senyawa tersebut rasanya pahit dan bersifat racun untuk binatang kecil seperti serangga, salah satunya kecoa. Sedangkan flavonoid adalah senyawa yang bersifat racun atau aleopati yang terdapat pada daun pandan wangi (Pandanus amaryllifolius). Racun tersebut bekerja dengan cara melumpuhkan sistem saraf dan sistem pernafasan. (Petijo, 2002).

Berdasarkan pernyataan tersebut diatas, peneliti tertarik untuk melakukan penelitian dengan judul penelitian "Pengaruh Berbagai Konsentrasi Air Perasan Daun Pandan Wangi (Pandanus ammaryllifolius) Sebagai Insektisida Terhadap Kematian KecoaTahun 2017”. Dengan harapan hasil penelitian dapat dijadikan sebagai suatu pemecahan masalah untuk mengurangi jumlah kecoa, sehingga kehidupan manusia tidak terganggu dengan kecoa.

\section{Bahan dan Metode}

Jenis penelitian yang digunakan pada penelitian ini adalah pra eksperimental dengan rancangan one shot case study. Variabel dependent yang digunakan berupa Kematian Kecoa, variabel independent berupa Konsentrasi Air Perasan Daun Pandan Wangi. Analisis statistik yang digunakan uji statistik Kruskal Wallis. Desain penelitian yang dipilih one shot case study yaitu sebuah eksperimen yang dilaksanakan tanpa adanya kelompok pembanding dan juga tanpa adanya tes awal.

Penelitian dilaksanakan di Rumah Peneliti, Jalan Kober Gang Cempaka No 30, Kecamatan Purwokerto Barat, Banyumas.

\section{Hasil dan Pembahasan}

Penelitian dilaksanankan di Rumah Peneliti, Jalan Kober Gang Cempaka No 30, Kecamatan Purwokerto Barat, Banyumas. Lokasi yang dekat dengan jalan raya sehingga mudah dijangkau oleh transportasi.

Peneliti melakukan penelitian di dapur, ruangan ini dilengkapi dengan ventilasi dilengkapi dengan kawat kasa, pencahayaan di ruangan ini dilengkapi dengan dua pencahayaan yaitu pencahayaan alami menggunakan sinar matahari dan pencahayaan buatan menggunakan lampu listrik.

1. Jenis Kecoa

Jenis Kecoa yang digunakan dalam penelitian ini adalah Kecoa Dewasa Periplaneta americana, karena pada fase dewasa, kecoa sangat mengganggu manusia. Kecoa Dewasa Periplaneta Americana didapatkan dari rumah.

Ciri-cirinya adalah (Terang Uli J. Sembiring \& Dewi Susanna, 2011) :

a) Panjang 35-40 mm, lebar 13-25 mm. 
b) Abdomen merah kecoklatan, dengan pronotus kuning keruh dan di bagian tengah terdapat sepasang bercak coklat

c) $\mathrm{Di}$ bagian belakang abdomen terdapat sepasang serkus yang relatif panjang, tipis dan runcing tak ubahnya sebagai cemeti.

d) Kecoa jantan mempunyai styli (umbai yang terdapat dibelakang dari perutnya)

e) Kecoa betina maupun jantan mempunyai serci

2. Jumlah Kecoa yang digunakan dalam penelitian Jumlah kecoa yang digunakan 35 ekor dengan masing-masing wadah berisi 5 ekor kecoa, kemudian diberi perlakuan menggunakan air perasan daun pandan wangi dengan cara disemprot menggunakan alat semprot.

\section{Air Perasan Daun Pandan Wangi}

Daun Pandan Wangi yang digunakan untuk membuat perasan diperoleh dari Kelurahan Kober, Kecamatan Purwokerto Barat, Banyumas. Ciri-ciri Daun Pandan Wangi yang digunakan daun memanjang, berukuran $60 \mathrm{~cm}$, berwarna hijau, beraroma wangi. Sedangkan pembuatan perasan dilakukan di rumah peneliti, Jalan Kober, Gang Cempaka No 30, Kecamatan Purwokerto Barat, Banyumas. Cara memperoleh perasan dengan ditumbuk sampai halus, kemudian diperas dan disaring menggunakan kain kasa. Konsentrasi masing - masing perasan adalah 5\%, 10\%, 15\%, 20\%, 25\%, 30\%, 35\%.

4. Ciri-ciri kerusakan organ pada kecoa setelah dikontakan dengan air perasan daun pandan wangi

Setelah dilakukan penyemprotan dengan air perasan daun pandan wangi, tubuh kecoa berubah. Kerapas menjadi kering, tubuh menyusut, toraks mengering. Karapas kecoa tidak sampai hancur, setelah diamati sampai 2 hari, tidak sama halnya dengan penggunaan insektisida anorganik. Ciri-ciri tersebut terjadi akibat dari senyawa saponin dan flavonoid yang bersifat racun terhadap serangga. (Indriantoro, 2010)

\section{Ciri-ciri kecoa akan mati}

Setelah dilakukan penyemprotan air perasan daun pandan wangi terhadap kecoa, peneliti mengamati ciriciri kecoa yang akan mati. Pada konsentrasi 30\% dengan lama paparan 1 jam sampai 2 jam, kecoa masih bergerak aktif. Tanda-tanda terjadi pada lama paparan 3 jam, dengan ciri-ciri kecoa lebih banyak diam dan akhirnya kecoa mati. Sama halnya dengan konsentrasi $30 \%$, bahwa pada konsentrasi 35\% dengan lama paparan 1 jam kecoa masih bergerak aktif. Tandatanda terjadi pada lama paparan 2 jam dan 4 jam, kecoa lebih banyak diam dan pada paparan 3 jam jam 5 jam kecoa mati.

\section{Kematian Kecoa Periplaneta americana}

Hasil pengamatan dan perhitungan jumlah kematian Kecoa Periplaneta americana setelah dikontakkan dengan air perasan daun pandan wangi konsentrasi 5\%, 10\%, 15\%, 20\%, 25\%, 30\%, 35\% dapat dilihat pada tabel berikut :

Tabel 4.2

Hasil Pengamatan jumlah kematian Kecoa Periplaneta americana

\begin{tabular}{|c|c|c|c|c|c|c|c|}
\hline \multirow{2}{*}{$\begin{array}{c}\text { Konsentrasi } \\
\text { Air Perasan } \\
\text { Daun } \\
\text { Pandan } \\
\text { Wangi } \\
\end{array}$} & \multicolumn{5}{|c|}{$\begin{array}{c}\text { Jumlah Kecoa yang } \\
\text { Mati pada Jam ke- }\end{array}$} & \multirow{2}{*}{$\begin{array}{c}\text { Total } \\
\text { Kematian } \\
\text { Kecoa }\end{array}$} & \multirow{2}{*}{ Keterangan } \\
\hline & 1 & 2 & 3 & 4 & 5 & & \\
\hline $5 \%$ & 0 & 0 & 0 & 0 & 0 & 0 & $\begin{array}{c}\text { Jumlah } \\
\text { Kecoa uji } 5 \\
\text { ekor }\end{array}$ \\
\hline $10 \%$ & 0 & 0 & 0 & 0 & 0 & 0 & $\begin{array}{c}\text { Jumlah } \\
\text { Kecoa uji } 5 \\
\text { ekor }\end{array}$ \\
\hline $15 \%$ & 0 & 0 & 0 & 0 & 0 & 0 & $\begin{array}{c}\text { Jumlah } \\
\text { Kecoa uji } 5 \\
\text { ekor }\end{array}$ \\
\hline $20 \%$ & 0 & 0 & 0 & 0 & 0 & 0 & $\begin{array}{c}\text { Jumlah } \\
\text { Kecoa uji } 5 \\
\text { ekor } \\
\end{array}$ \\
\hline $25 \%$ & 0 & 0 & 0 & 0 & 0 & 0 & $\begin{array}{c}\text { Jumlah } \\
\text { Kecoa uji } 5 \\
\text { ekor }\end{array}$ \\
\hline $30 \%$ & 0 & 0 & 0 & 2 & 0 & 2 & $\begin{array}{c}\text { Jumlah } \\
\text { Kecoa uji } 5 \\
\text { ekor }\end{array}$ \\
\hline $35 \%$ & 0 & 0 & 2 & 0 & 2 & 4 & $\begin{array}{c}\text { Jumlah } \\
\text { Kecoa uji } 5 \\
\text { ekor }\end{array}$ \\
\hline
\end{tabular}

Tabel diatas menunjukan bahwa kematian kecoa berbeda - beda. Artinya pemberian konsentrasi Air Perasan Daun Pandan Wangi yang digunakan mempengaruhi jumlah kematian kecoa Periplaneta americana.

7. Data Hasil Uji Statistik

Tabel 4.3

Hasil Analisis Uji Kruskal Wallis

\begin{tabular}{ccccc}
\hline No & Konsentrasi & $\begin{array}{c}\text { Rata-rata } \\
\text { Rangking }\end{array}$ & Signifikansi & Keterangan \\
\hline 1 & $5 \%$ & 16,5 & 0,162 & Ho Diterima \\
\hline 2 & $10 \%$ & 16,5 & 0,162 & Ho Diterima \\
\hline 3 & $15 \%$ & 16,5 & 0,162 & Ho Diterima \\
\hline 4 & $20 \%$ & 16,5 & 0,162 & Ho Diterima \\
\hline 5 & $25 \%$ & 16,5 & 0,162 & Ho Diterima \\
\hline 6 & $30 \%$ & 20,0 & 0,162 & Ho Diterima \\
\hline 7 & $35 \%$ & 23,5 & 0,162 & Ho Diterima \\
\hline
\end{tabular}


Hasil uji statistik Kruskal Wallis diperoleh nilai $\mathrm{K}=0,162 \geq \alpha 0,05$ maka Ho diterima yang berarti tidak ada pengaruh berbagai konsentrasi air perasan daun pandan wangi (Pandanus ammaryllifolius) sebagai insektisida terhadap kematian kecoa.

\section{Kesimpulan}

1. Air perasan daun pandan wangi mampu membunuh kecoa.

2. Konsentrasi yang mampu membunuh kecoa adalah konsentrasi 30\% membunuh 2 ekor kecoa dengan lama paparan 4 jam, dan konsentrasi 35\% membunuh 4 ekor kecoa dengan lama paparan 3 jam dan 5 jam.

3. Konsentrasi efektif untuk membunuh kecoa dari perlakuan adalah konsentrasi 35\%.

4. Tidak ada pengaruh pemakaian air perasan daun pandan wangi terhadap kematian kecoa menggunakan uji Statistik Kruskal Wallis dengan hasil nilai $\mathrm{K}=0,162 \geq \alpha 0,05$.

\section{Ucapan Terima kasih}

Peneliti mengucapkan terima kasih kepada Pembimbing KTI, Bapak Dr. Djamaluddin Ramlan, SKM, M.Kes yang telah memberikan bimbingan dan saran-sarannya.

\section{Daftar Pustaka}

Amalia, Herma \& Harahap, Sakti, Idham, 2010. Preferensi Kecoa Amerika Periplaneta americana (L.) (Blattaria: Blattidae) terhadap Berbagai Kombinasi Umpan. Bogor : Departemen Proteksi Tanaman Institusi Pertania Bogor

Bagyono, Tuntas, 2013. Kunci Praktis untuk Metodologi Penelitian Kesehatan PromotifPreventif. Yogyakarta : Penerbit Ombak

Borror, J, Donald (Alm), dkk, 1992. Pengenalan Pelajaran Serangga Edisi keenam. Yogyakarta : Gajah Mada University Press

Cahyono, Tri, 2014. Pedoman Penulisan Proposal Penelitian dan Karya Tulis Ilmiah/Skripsi Edisi Revisi Ketiga. Purwokerto :Kementerian Kesehatan RI Politeknik Kesehatan Jurusan Kesehatan Lingkungan Purwokerto

Darsatop.lecture.ub.ac.id, diakses tanggal 11/10/2016, pukul 10.15 WIB

Direktorat Jenderal Pemberantasan Penyakit Menular dan Penyehatan Lingkungan,2002, Pengendalian Kecoa di Rumah Sakit, Jakarta : Direktorat Jenderal Pemberantasan Penyakit Menular Dan Penyehatan Lingkungan.

Endi Ridwan, 2013, Etika Pemenfaatan Hewan Percobaan Dalam Penelitian Kesehatan,
Jakarta: Komite Etik Penelitian Kesehatan Fakultas Kedokteran Universitas Indonesia.

Environmental Health Watch, 2005. Factsheet Cockroach control guide. Environmental Health Watch

Hastuti, H, 2008. Daya Bunuh Ekstrak Daun Pandan Wangi (Pandanus amaryllifolius Roxb.) terhadap Larva Anopheles aconitus Donitz. Skripsi : Fakultas Kedokteran UNS : Surakarta

Indonesia Depdikbud, 1995. Kamus Besar Bahasa Indonesia Edisi kedua. Jakarta:Balai Pustaka.

Indonesia, Departemen Kesehatan RI. DIT. JEN. PPM dan PLP, 1987, Ekologi Vektor Dan Beberapa AspekPerilaku, Jakarta.,2000, Indonesia Sehat 2010, Jakarta.

Indriantoro.H. 2010. Efek Larvasida Ekstrak Daun Cengkeh (Syzygium Aromaticum L) terhadap Aedes aegypti L. Skripsi Fakultas Kedokteran Sebelas Maret : Surakarta.

Iskandar, Adang, dkk, 1985.Pemberantasan Serangga dan Binatang Pengganggu. Jakarta:Proyek Pengembangan Pendidikan Tenaga Sanitasi Pusat Pusdiknakes.

Lesmana, D, 2003. Aktivitas Repelensi Ekstrak Sepuluh Tanaman Terhadap Blatella germanica L. Jurusan Hama dan Penyakit Tumbuhan, Fakultas Pertanian, Institusi Pertanian Bogor

Li, J \& Ho, SH 2003, Pandan Leaves (Pandanus amaryllifolius Roxb.) As A Natural Cockoach Repellent, School of Biological Sciences, National University of Singapore

Permatasari, Indah, 2008. Studi Identifikasi Kecoa dan Kepadatannya di Rumah Sakit Umum Kardinah Kota Tegal Tahun 2008. KTI : Jurusan Kesehatan Lingkungan Purwokerto Poltekkes Semarang

Pratama, Ary, Bangkit, dkk, 2008. Pemanfaatan Ekstrak Daun Pandan Wangi (Pandanus amaryllifolius Roxb.) Sebagai Larvasida Alami. Jurnal : Fakultas Ilmu Kesehatan Universitas Muhammadiyah Surakarta : Surakarta

Putra, Susetya, Nugroho, 1994. Serangga di Sekitar Kita. Yogyakarta : Penerbit Kanisius

Ratnasari, Anilia, Efisiensi Larutan Antiseptik Ekstrak Daun Cegkeh (Syzygium aromatikum L) Untuk Mortalitas Kecoa Sebagai Hama Pemukiman. FKIP Universitas Wiralodra : Jawa Barat

Rozendaal, JA 1997, Vector Control Methods For Use by Individuals and Conmmunities, World Health Organization, Geneva.

Santjaka, Aris, 2011. Statistik untuk Penelitian Kesehatan. Yogyakarta : Nuha Medika 
Sembel, T, Dantje, 2009. Entomologi Kedokteran. Yogyakarta : ANDI

Sembiring, Uli, J, Terang, \& Susanna, Dewi, 2011. Entomologi Kesehatan (Artropoda Pengganggu Kesehatan dan Parasit yang Dikandung). Jakarta : Penerbit Universitas Indonesia (UI-Press)

Siswoyowati, 2006. Studi Pengendalian Serangga dan Tikus pada Rumah Sakit Islam Purwokerto Tahun 2006. KTI : Jurusan Kesehatan Lingkungan Purwokerto Poltekkes Semarang

Susilowati, \& Widyastuti, Kiki, 2004. Farmakognosi. Yogyakarta : SMF 